\title{
W.M. Wiersinga, G.J. Kahaly (eds): Graves' Orbitopathy: A Multidisciplinary Approach
}

\author{
Amsterdam, Mainz, 2007, XIV + 260 p., 83 fig., 47 in color, 38 tab., soft cover, \\ ISBN 978-3-8055-8342-8 KARGER, CHF 166.00 / EUR 118.50 / USD 166.00
}

\author{
Joachim Esser
}

Received: 7 January 2009 / Accepted: 14 January 2009/Published online: 18 February 2009

(C) Springer-Verlag 2009

The coordination of 31 authors to write a companion on a single complex of symptoms is a difficult task at best. In this particular case, Wilmar Wiersinga (Amsterdam) and Georges Kahaly (Mainz) have chosen the right combination of endocrinologists and ophthalmologists, who shed light on all aspects of Graves' Orbitopathy (GO) from their respective points of view.

Graves' orbitopathy is an orbital inflammation that is in the majority of cases associated with autoimmune thyroid disease. To adequately represent this complex of symptoms, a multidisciplinary approach is required; the inclusion of competent endocrinologists and experienced orbital surgeons has been managed superbly by the editors. The authors represent the European Group on Graves' Orbitopathy (EUGOGO) which is recruited from 13 clinical centers in eight European countries.

The layout and concept make this book very readable and practical. To each of the 23 chapters, about 10-20 clinically relevant questions are given (e.g. "What signs are helpful for assessing severity? What is apical crowding? What should you do if steroids fail? Is botulinum toxin useful?"). These questions are promptly answered in a way that makes this book also useful as a clinic manual. Special and difficult cases, such as GO in children or diabetics, are also included. A number of summaries lend insight into standardized examination techniques and patient management. Patient management differentiates between different grades of severity, and offers recommendations concerning the inclusion of specialists in disease management. It is a timely and up-to-date book, and is in accordance with the EUGOGO consensus recommendations which were published in 2008 in Thyroid and the European Journal of Ophthalmology.

This book would be a valuable asset for ophthalmologists.

\footnotetext{
J. Esser $(\bowtie)$

Abteilung für Erkrankungen der vorderen

Augenabschnitte/Orthoptik, Universitäts Augenklinik Essen,

Hufelandstrasse 55,

45122 Essen, Germany

e-mail: joachim.esser@uni-essen.de
} 